\title{
Matrix metalloproteinase-7 may serve as a novel biomarker for cervical cancer
}

This article was published in the following Dove Press journal:

OncoTargets and Therapy

\author{
Linyan Zhu* \\ Xiaojiao Zheng* \\ Yongming Du \\ Yan Xing \\ Kejun Xu \\ Lining Cui
}

Department of Obstetrics and Gynaecology, Ningbo First Hospital, Ningbo, Zhejiang, People's Republic of China

*These authors contributed equally to this work
Correspondence: Lining Cui

Department of Obstetrics and Gynaecology, Ningbo First Hospital, 9 Liuting Street, Ningbo, Zhejiang 315000, People's Republic of China Email cuilining@hotmail.com
Background: The biological and clinical significance of matrix metalloproteinase-7 (MMP-7) in cervical cancer remains unknown. Here, we investigated the function of MMP-7 in cervical cancer cells and evaluated its clinical significance in both tissues and serum from cervical cancer patients.

Methods: First, we analyzed the expression of MMP-7 in cervical cancer using Oncomine microarray data and examined its expression in cervical tissues by quantitative real-time polymerase chain reaction and Western blotting. Second, we utilized gene silencing to explore the role of MMP-7 in cells. Finally, we examined the MMP-7 levels in patients with cervical cancer and normal serum by enzyme-linked immunosorbent assay. Moreover, we further investigated the relationship between MMP-7 expression and pathological features.

Results: The mRNA and protein MMP-7 levels were higher in cervical cancer tissues than in healthy controls. Silencing of MMP-7 significantly decreased cervical cancer cell proliferation, migration, and invasion. The serum MMP-7 levels were significantly higher in cervical cancer patients than in healthy subjects $(P<0.01)$. Further, higher MMP-7 expression was associated with increased lymph metastasis $(P=0.021)$, pathological grade $(P=0.039, P=0.047)$, and clinical stage $(P=0.049, P=0.046)$.

Conclusion: MMP-7 appears to act as an oncogene in cervical cancer cells and is involved in cell proliferation, migration, and invasion. MMP-7 expression was significantly higher in the tissue and serum of cervical cancer patients compared to healthy individuals and was correlated with increased pathalogical grade, clinical stage, and lymph metastasis. Therefore, our data provide novel evidence that MMP-7 may be a clinically relevant biomarker for cervical cancer.

Keywords: cervical cancer, matrix metalloproteinase-7, biomarker, migration, invasion

\section{Introduction}

Cervical cancer is the fourth most common cancer worldwide. ${ }^{1}$ In 2015 , it was estimated that there were 98,900 cases of cervical cancer and 30,500 deaths from this disease in China. ${ }^{2}$ Previous studies have reported that good quality screening has helped to decrease both incidence and mortality by $80 \%-90 \%$ in developed countries. ${ }^{3}$ However, patients in developing countries who present with metastasis or recurrence exhibit lower survival than those with primary cancer. Therefore, there is a need for prognostic factors to predict the prognosis of cervical cancer patients. ${ }^{4}$

An ideal tumor marker should have high sensitivity and high specificity to discriminate between patients with cancer and either healthy controls or those with benign conditions. ${ }^{5}$ Squamous cell carcinoma antigen (SCC-Ag) is the most commonly used tumor marker for squamous cell cervical carcinoma. However, increased serum SCC-Ag levels are commonly observed not only in squamous cell carcinoma of the cervix but also in squamous cell carcinoma of the esophagus, lungs, head and neck, 
and anus. Further, SCC-Ag levels may also be increased in benign diseases such as skin disorders, pelvic inflammatory disease, cystitis, and renal failure. ${ }^{5,6}$ Some authors have reported that SCC-Ag has no prognostic value, ${ }^{7}$ while others have found that it is an independent prognostic variable for clinical outcomes. ${ }^{8,9}$ Despite these conflicting reports, serum SCC-Ag levels at the time of diagnosis are reported to correlate with tumor stage, size, depth of invasion, parametrial invasion, and lymph node metastasis. ${ }^{5,10}$

Tumor metastasis is a complex process encompassing a succession of changes including loss of cell-cell and cell-matrix adhesion, degradation of extracellular matrix (ECM), and induction of angiogenesis. ${ }^{11}$ The tumor extracellular microenvironment plays fundamental roles in tumor development and progression. Matrix metalloproteinases (MMPs) belong to a family of zinc proteases ${ }^{12}$ that promote cancer occurrence and invasion. Structurally, MMP-7 is one of the smallest MMPs and is known to be a secreted zinc- and calcium-dependent endopeptidase. ${ }^{13}$ Functionally, MMP-7 degrades a broad range of ECM components and can both cleave other substrates and activate other proteinases. ${ }^{14,15}$ As MMP-7 acts on such a broad spectrum of substrates, it plays a critical role in regulating a diverse array of cellular processes, such as cell apoptosis, matrix remodeling, and epithelial-mesenchymal transition (EMT). ${ }^{16}$ MMPs are essential regulators of ECM turnover. ${ }^{17}$ Currently, the role of the tumor microenvironment in cervical cancer progression is widely recognized, while studies of the biological functions and molecular mechanisms of MMPs in cervical cancer are limited.

Recent studies have found that the human papillomavirus (HPV) 16 E6 and E7 oncoproteins can promote cervical cancer invasiveness by upregulating 2 specific MMPs: MMP-2 and MT1-MMP. ${ }^{18}$ MMP-7 is a member of the MMP family, but unlike other members of this family, it is expressed by tumor cells themselves rather than by the stromal cells, ${ }^{19,20}$ indicating that MMP-7 could be useful as a tumor-associated biological marker. Clinical studies have found that overexpression of MMPs is closely associated with tumor invasion and metastasis. ${ }^{21} \mathrm{MMP}-7$ was reported to be a malignant biomarker in ovarian cancer, ${ }^{22-24}$ and the expression level of MMP-7 was higher in invasive, metastatic ovarian cancer. MMP-7 may also contribute to the development of gastric adenocarcinoma ${ }^{25}$ and colorectal cancer. ${ }^{26}$ These findings suggest that MMP-7 may play an important role in the development and progression of malignant tumors. To our knowledge, it remains unclear whether MMP-7 contributes to the development of cervical cancer.

In this study, we aimed to analyze MMP-7 expression in cervical cancer tumor tissue and patient serum and to investigate the role of MMP-7 in cell proliferation, invasion, and migration in cervical cancer cell lines. In this work, we have confirmed that MMP-7 is an effective prognostic biomarker in cervical cancer.

\section{Materials and methods Clinical samples}

Cervical tissue samples and matched adjacent non-cancerous tissues were collected from 15 patients treated in the Department of Gynaecology and Obstetrics at Ningbo First Hospital (Zhejiang, China) between 2013 and 2017. Fresh samples, including tumor tissues and paracancerous cervical tissues, were obtained from cervical cancer patients during tumor resection. Serum samples from 90 patients with cervical cancer were obtained between July 2014 and August 2017 by the Department of Gynaecology and Obstetrics at Ningbo First Hospital and stored at $-80^{\circ} \mathrm{C}$ until required. Clinical parameters including age, International Federation of Gynecology and Obstetrics (FIGO) stage, tumor size, histological grade, invasion depth, lymphatic metastasis, and HPV genotyping were acquired from hospitalization records. These data are illustrated in Table 1. The control group was composed of 30 healthy individuals. Patients and healthy individuals with known allergies and severe infections were excluded from the present study.

All human tissue and serum analyses performed in our study were approved by the Ethics Committee and Institutional Review Board of Ningbo First Hospital, China (protocol number R001). Written informed consent for the scientific use of the biological material was obtained from each patient,

Table I Clinical characteristics of cervical cancer patients

\begin{tabular}{ll}
\hline Characteristics & Data (N=90) \\
\hline Age & \\
$>45$ & $16(17.8 \%)$ \\
$\leq 45$ & $74(82.2 \%)$ \\
FIGO stage & \\
I-II & $70(77.8 \%)$ \\
III-IV & $20(22.2 \%)$ \\
Tumor size & \\
$\quad<2$ cm & $55(61.1 \%)$ \\
$\geq 2$ cm & $35(38.9 \%)$ \\
Histological grade & \\
$\quad$ GI+G2 & $60(66.7 \%)$ \\
G3 & $30(33.3 \%)$ \\
Invasion depth & \\
$\quad<0.5$ & $51(56.7 \%)$ \\
$\geq 0.5$ & $49(54.4 \%)$ \\
Lymphatic metastasis & \\
$\quad$ No & $69(76.7 \%)$ \\
Yes & $21(23.3 \%)$ \\
HPV genotyping & \\
HPVI6(+) & $46(5 I .1 \%)$ \\
HPVI8(+) & $15(16.7 \%)$ \\
\hline Abbreviation
\end{tabular}

Abbreviation: FIGO, International Federation of Gynecology and Obstetrics; $\mathrm{HPV}$, human papillomavirus. 
and all procedures were performed in accordance with the guidelines of the China Ethical Review Committee.

\section{Bioinformatic analysis of MMP-7 expression using Oncomine cancer gene microarray database}

Datasets in the Oncomine database (https://www.oncomine.org/ resource/login.html) contain information from gene microarrays of cancers and corresponding benign tissues. The level of MMP-7 gene expression in cervical cancer was analyzed using Oncomine.${ }^{27}$ For this analysis, we compared datasets from cancer vs normal patients. $P<0.05$, fold change $=2$, and top $10 \%$ gene rank were used as the threshold values. Subsequently, the $\log 2$ median-centered intensity and the 10 and 90th percentile data from Oncomine were plotted using GraphPad Prism software (version 5.0; GraphPad Software Inc., La Jolla, CA, USA). All statistical analyses were carried out using SPSS 19.0 (SPSS Inc., Chicago, IL, USA) for Windows (IBM, Armonk, NY, USA). $P<0.05$ was considered statistically significant.

\section{RNA isolation from patient specimens and quantitative real-time polymerase chain reaction (PCR)}

A total of 15 cervical cancer tumor tissues and 15 matched adjacent non-cancerous tissues were frozen in liquid nitrogen and stored at $-80^{\circ} \mathrm{C}$ until RNA extraction. Total tissue RNA was extracted from fresh surgically removed unfixed tumor samples using Trizol reagent (Takara, Tokyo, Japan) and reverse transcribed using the PrimeScript RT-PCR kit (Takara) according to the manufacturer's protocol. MMP-7 mRNA expression was determined by real-time PCR (primers are listed in Table S1) using SYBR Premix Ex Taq (Takara) on a 7300 real-time PCR system (Applied Biosystems, FosterCity, CA, USA) using the following cycling conditions: an initial $10 \mathrm{~s} \mathrm{step}$ at $95^{\circ} \mathrm{C}$ followed by 40 cycles of $5 \mathrm{~s}$ at $95^{\circ} \mathrm{C}$ and $31 \mathrm{~s}$ at $60^{\circ} \mathrm{C}$. Data shown are normalized to GAPDH expression and represent the average of 3 repeated experiments.

\section{Cell culture}

The human cervical cancer cell lines Hela and Caski were purchased from the Cell Bank of the Chinese Academy of Science. Cells were cultured in RPMI 1640 medium (Gibco, Beijing, China) supplemented with 10\% (v/v) fetal bovine serum (Gibco) at $37^{\circ} \mathrm{C}$ in an incubator with $5 \% \mathrm{CO}_{2}$.

\section{Small interfering RNA knockdown}

Small interfering RNA (siRNA) duplexes targeting MMP-7 and a scramble control siRNA duplex were obtained from
GenePharma (Shanghai, China). Transfection was performed using the Lipofectamine RNAiMAX Reagent (Invitrogen, Carlsbad, CA, USA) according to the manufacturer's instructions.

\section{Cell viability assay}

Control and siRNA-MMP-7 cervical cancer cells, Hela and Caski, were plated in 96-wells plates at a density of 2,500 cells per well in $100 \mu \mathrm{L}$ of complete culture medium per well. Each group contained 5 wells. Ten microliters of Cell Counting Kit-8 (CCK8; Dojindo, Kumamoto, Japan) solution was added to each well after $0 \mathrm{~h}, 24 \mathrm{~h}, 48 \mathrm{~h}$, and $72 \mathrm{~h}$. Metabolism of CCK8 solution produces a colorimetric dye that was detected at $450 \mathrm{~nm}$ using a microplate reader. The experiment was repeated 3 times.

\section{Wound healing assay}

Cells were grown to confluence in 6-well plates, and then a wound was created by scraping with a pipette tip. Photographs were taken at the indicated time points to assess the ability of the cells to migrate into the wound area. Experiments were carried out in triplicate at least 3 times.

\section{In vitro invasion assays}

Transwell invasion assays were carried out by adding $100 \mu \mathrm{L}$ of Matrigel (BD Bioscience, Franklin Lakes, NJ, USA) into the upper chamber of the transwell and placing $5 \times 10^{4}$ cells onto the Matrigel. After 48 hours, cells that invaded through the membrane filter were fixed, stained with crystal violet, counted, and imaged. At least 5 grids per field were counted. All assays were independently repeated 3 times.

\section{Assessment of serum MMP-7 levels}

Blood samples were collected and centrifuged at $1,000 \times g$ at $4^{\circ} \mathrm{C}$ for $15 \mathrm{~min}$ to separate the supernatant. Serum MMP-7 was detected with an enzyme-linked immunosorbent assay (ELISA) kit (cat no CSB-E04679h; Cusabio Biotech Co, Ltd, Wuhan, China) according to the manufacturer's protocol. Finally, the optical density of each well was measured at $450 \mathrm{~nm}$ using an ELISA analyzer, and the sample concentration was calculated based on a standard curve. Receiver operating characteristic (ROC) curve analysis was applied to assess the diagnostic value of MMP-7 in cervical cancer. All statistical analyses were performed using SPSS 19.0 for Windows. Statistical significance was determined to be $P \leq 0.05$. 


\section{Western blotting}

Whole cell lysates were prepared in lysis buffer $(50 \mathrm{mM}$ Tris$\mathrm{HCl} ; 150 \mathrm{mM} \mathrm{NaCl} ; 1 \%$ Triton-X 100; $1 \mathrm{mM}$ each $\mathrm{MgCl}$, $\mathrm{MnCl} 2$, and $\mathrm{CaCl} 2 ; 1 \mathrm{mM}$ Phenylmethanesulfonyl fluoride; and $10 \mathrm{mM}$ sodium fluoride). ${ }^{28}$ Thirty micrograms of total protein was loaded in each well of a $15 \%$ gel, separated by electrophoresis, and transferred to a nitrocellulose membrane. After blocking with 5\% nonfat milk and incubating with primary antibodies at $4{ }^{\circ} \mathrm{C}$ overnight, the membranes were incubated with the secondary antibody for $2 \mathrm{~h}$ at room temperature. The signal was detected for 1 min using enhanced chemiluminescent solution (Advansta, Menlo Park, CA, USA) and the ChemiDoc XRS imaging system (Bio-Rad Laboratories Inc., Hercules, CA, USA). The primary antibodies used include the following: MMP-7 (Abcam, Cambridge, UK) and $\beta$-actin (Abcam). Anti- $\beta$-actin antibodies were used as an internal control. Quantification was performed using ImageJ software.

\section{Statistical analysis}

Data are presented as the means \pm standard error of the mean. Statistical analyses were performed using SPSS 19.0 for Windows. The area under the ROC curve was used to assess the feasibility of serum MMP-7 as a biomarker for cervical cancer. The chi-squared test or Student's $t$-test were used for comparisons between groups. Values of $P<0.05$ were considered statistically significant.

\section{Results}

\section{MMP-7 protein and mRNA expression levels are increased in cervical cancer tissues}

To further explore the clinical significance of MMP-7, we first analyzed the expression of MMP-7 in cervical cancer using Oncomine microarray data (https://www.oncomine.org/ resource/login.html). In a dataset from Biewenga, the expression of MMP-7 was increased in 40 cervical squamous cell carcinoma tissues compared to 5 normal tissues (Figure 1A). MMP-7 expression was significantly higher in 32 cervical squamous cell carcinoma tissues than in 21 cervical squamous epithelium and 3 cervix uteri from the Scotto Cervix dataset (Figure 1B). Moreover, the expression of MMP-7 was higher in 24 cervical cancer samples than in normal cervix uteri $(n=10)$ from the Oncomine Zhai Cervix dataset (Figure 1C). There was no statistical significance in Pyeon Multi-cancer datasets.

To compare the expression levels of MMP-7 in cervical cancer tissues and normal cervical tissues, we performed quantitative real-time PCR and Western blotting on cervical cancer tissue samples and matched adjacent non-cancerous tissues. The results showed that MMP-7 mRNA levels were clearly increased in the 15 cervical cancer tissue samples compared to the matched adjacent non-cancerous tissues (Figure 1D) and that MMP-7 protein levels were also significantly higher in the 9 cervical cancer samples than in the matched normal cervical cancer samples (Figure 1E) (among the 15 tissue pairs, the protein from 6 pairs was degraded). Densitometric analysis of the Western blot results is shown in Figure 1F.

\section{Knockdown of MMP-7 expression decreased cervical cancer cell proliferation, migration, and invasion}

Given that the expression of MMP-7 as well as cell proliferation and migration is associated with cervical cancer metastasis, we investigated the effect of silencing MMP-7 expression on cervical cancer cell proliferation and migration. Hela and Caski cells, both of which express high levels of MMP-7 determined by real-time PCR and Western blot analysis (Figure $\mathrm{S} 1$ ), were transfected with a specific small interfering RNA targeting MMP-7 (siRNA-MMP-7). The expression of MMP-7 protein in siRNA-MMP-7-treated Hela and Caski cells was significantly downregulated compared with cells transfected with a control siRNA (Figure 2).

Further functional studies demonstrated that knockdown of MMP-7 significantly decreased the proliferation of Hela and Caski cells (Figure 3). In addition, the migratory capacity of siRNA-MMP-7-transfected Hela and Caski cells was remarkably decreased compared with controls, as demonstrated by an in vitro wound healing assay (Figure 4). Moreover, knockdown of MMP-7 also suppressed cervical cancer cell invasion in vitro, as demonstrated by the transwell invasion assay (Figure 5).

Taken together, these data indicated that silencing of MMP-7 in cervical cancer cells suppressed cell proliferation, migration, and invasion in vitro.

\section{Serum MMP-7 levels are significantly higher in patients with cervical cancer compared with healthy individuals}

Secreted proteins are ideal candidates for diagnostic and prognostic markers, as they can be easily detected in the serum of patients. As MMP-7 is a secreted protein, we aimed to determine its diagnostic value in cervical cancer patients. We measured the serum levels of MMP-7 in 30 healthy people and 90 cervical cancer patients. The results showed that serum MMP-7 levels in cervical cancer patients and healthy people were $1,082.26 \pm 139.63 \mathrm{pg} / \mathrm{mL}$ and 


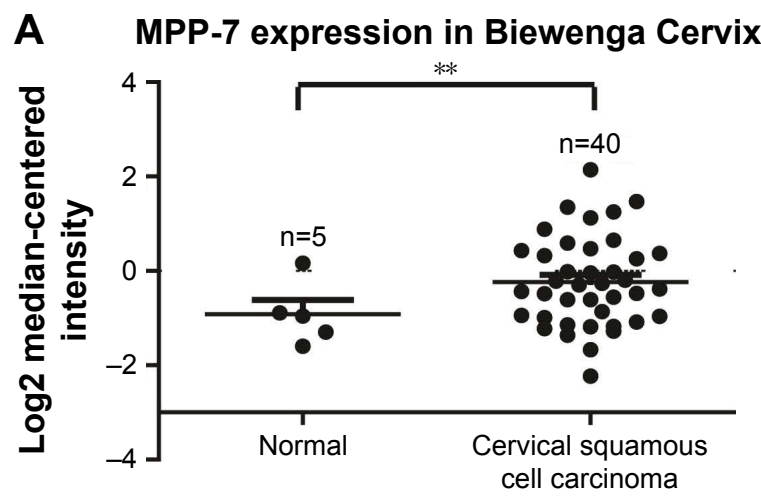

C MPP-7 expression in Zhai Cervix

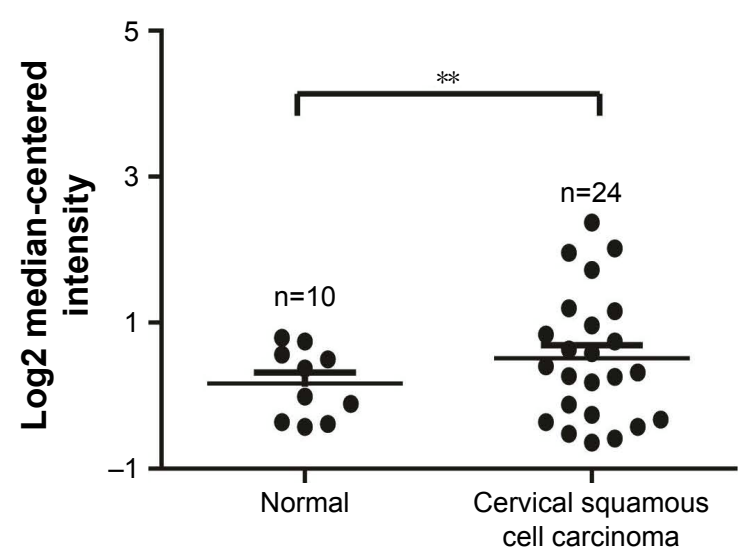

E

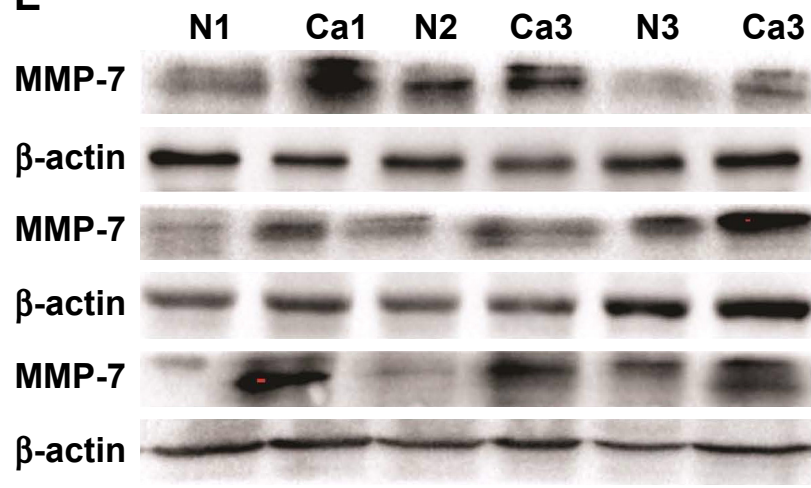

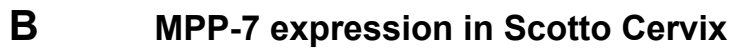

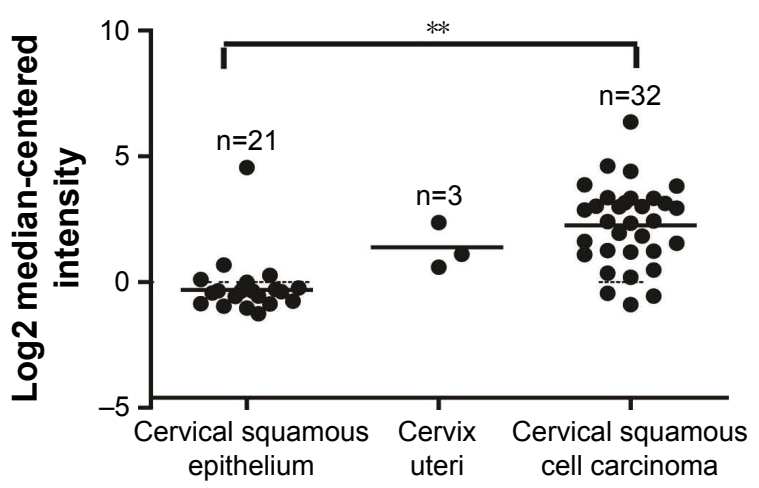

D

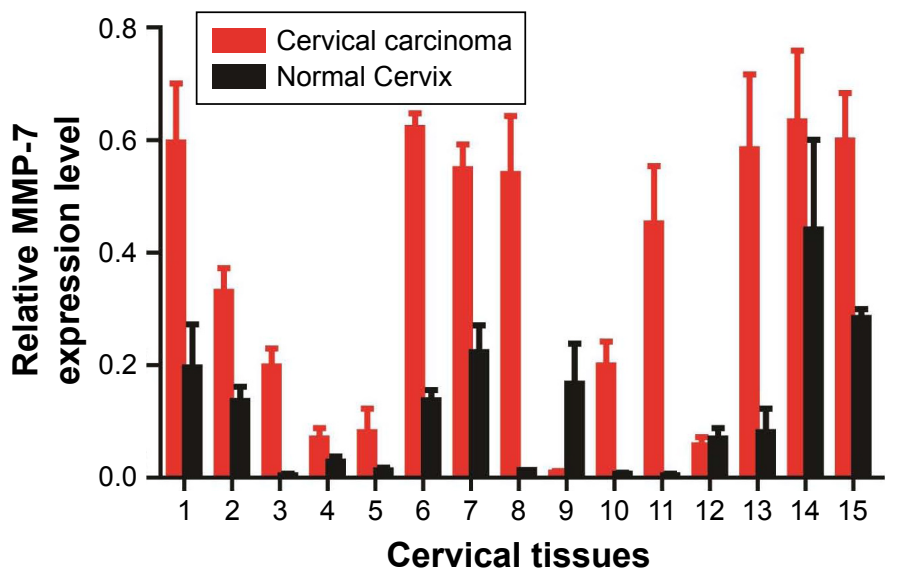

$\mathbf{F}$

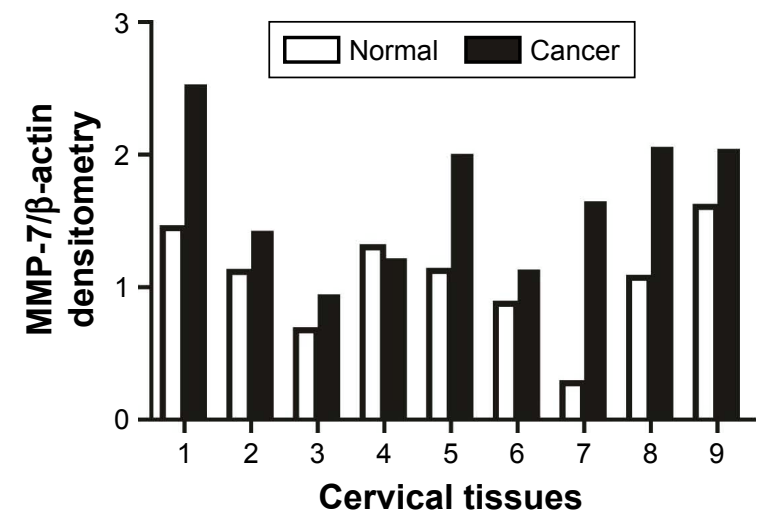

Figure I Expression of matrix metalloproteinase-7 (MMP-7) is significantly upregulated in cervical cancers.

Notes: (A) MMP-7 mRNA expression is upregulated in cervical squamous cell carcinoma tissues compared with normal cervical tissues, as revealed by the Oncomine Biewenga Cervix dataset. (B) MMP-7 mRNA expression is upregulated in cervical squamous cell carcinoma tissues compared with cervical squamous epithelium, as revealed by the Oncomine Scotto Cervix dataset. (C) MMP-7 mRNA expression is upregulated in cervical squamous cell carcinoma tissues and high-grade squamous intraepithelial neoplasia compared with normal cervical tissues, as revealed by the Oncomine Zhai Cervix dataset. (D) Relative mRNA expression levels of MMP-7, as determined by quantitative real-time polymerase chain reaction, in 15 pairs of cervical cancer tissues and paracancerous tissues. (A-D) Values are presented as the means \pm standard error of the mean; ${ }^{* * P}<0.01$. (E) Western blot analysis of MMP-7 expression in 9 pairs of cervical cancer samples and normal controls. $\mathrm{C}$ represents cervical cancer tissues and $\mathrm{N}$ represents normal control tissues. (F) Densitometric analysis of these results, using $\beta$-actin as a loading control.

864.39 $\pm 188.87 \mathrm{pg} / \mathrm{mL}$, respectively. Thus, the concentrations of MMP-7 were significantly higher in the serum of cervical cancer patients than in healthy people. The difference between healthy controls and cervical cancer patients was significant ( $P=0.0056$ ) (Figure 6A). As serum SCC-Ag is a clinically used diagnostic and prognostic marker for cervical cancer, the differences in serum SCC-Ag levels between healthy controls and cervical cancer patients was predictably significant $(P<0.0001)$ (Figure 6B). Next, we drew ROC curves for MMP-7, SCC-Ag, and MMP-7 and SCC-Ag 
A

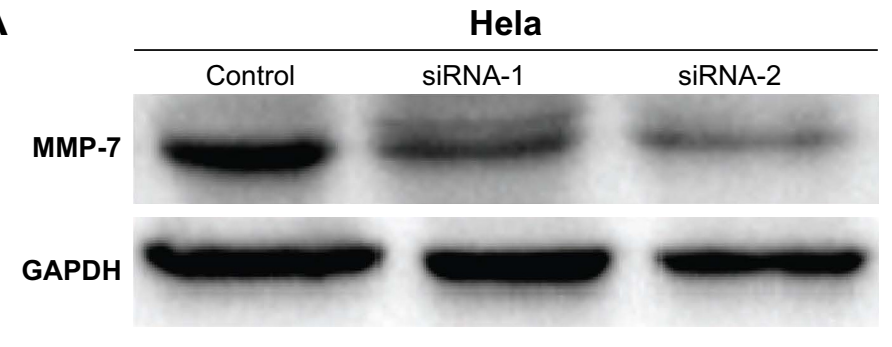

C

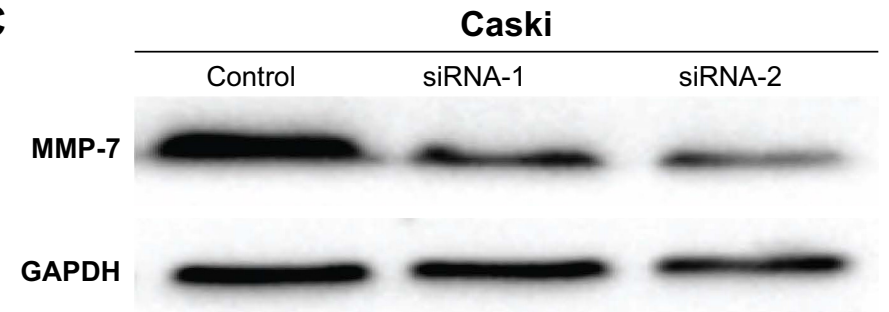

B

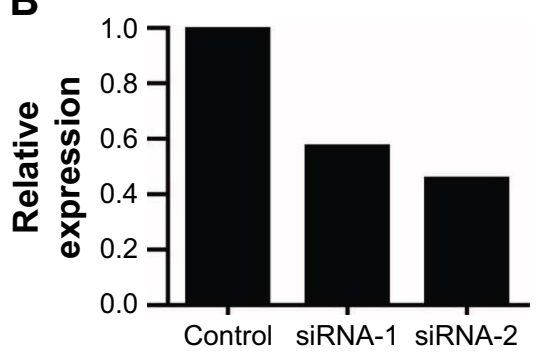

D

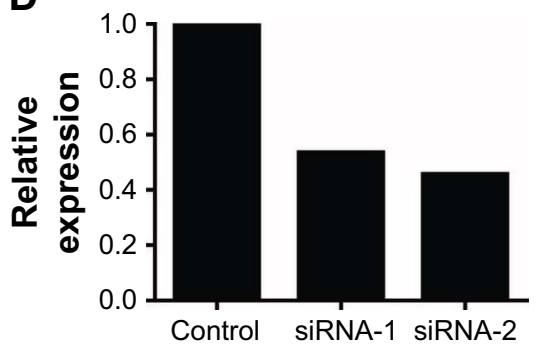

Figure 2 Silencing of matrix metalloproteinase-7 (MMP-7) significantly decreases MMP-7 expression.

Notes: Silencing of MMP-7 in Hela $(\mathbf{A})$ and Caski $(\mathbf{C})$ cells significantly decreased the expression of MMP-7 protein as detected by Western blot analysis. The results were normalized to $\beta$-actin expression, as shown in B and D. siRNA-I: 5'-ACC CAT TTG ATG GGC CAG GAA-3'; siRNA-2: 5'-TGC AGT GAT GTA TCC AAC CTA-3'.

combined to assess the value of MMP-7 as a serum marker for cervical cancer. The overall classification accuracy of MMP-7 for diagnosing cervical cancer was $65.0 \%$, with $46.7 \%$ sensitivity and $86.7 \%$ specificity (Table 2 ). A multivariate function combining measurement of SCC-Ag and MMP-7 serum concentrations improved overall sensitivity for detection of cervical cancer to $80.6 \%$. Combining the measurement of these 2 markers can improve the area under ROC curve to $0.806 \pm 0.047$ (Figure 6C).

The results also showed that levels of MMP-7 were higher in patients with lymph metastasis than in non-lymph metastasis patients $(P=0.021$, Figure $7 \mathrm{~A})$. We also found that concentrations of MMP-7 were significantly higher in the serum of patients with pathology grades 3 and 1-2 than in healthy individuals ( $P=0.039, P=0.047$, Figure 7B). There was some difference in MMP-7 levels in patients with clinical stage I-IV compared with healthy individuals $(P=0.049$, $P=0.046$, Figure 7C).

There was no statistically significant difference between patients with depth of invasion $\geq 0.5$ compared with depth of invasion $<0.5(P=0.817$, Figure $7 \mathrm{D})$. There was no statistically significant difference in MMP-7 levels
A

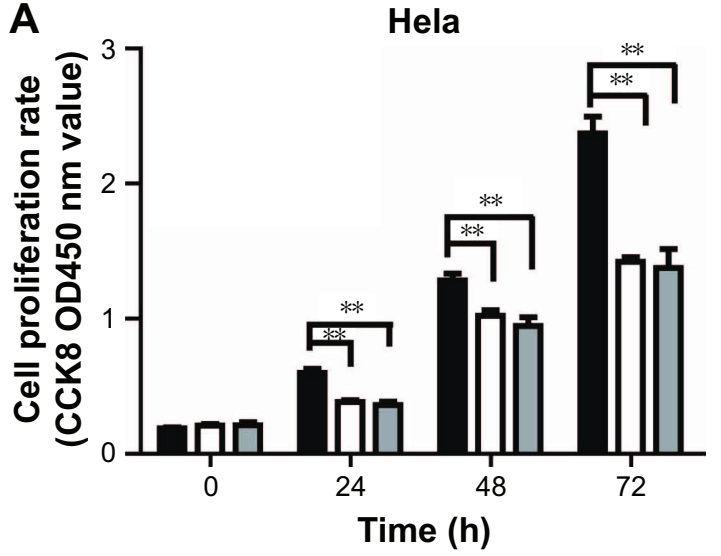

B

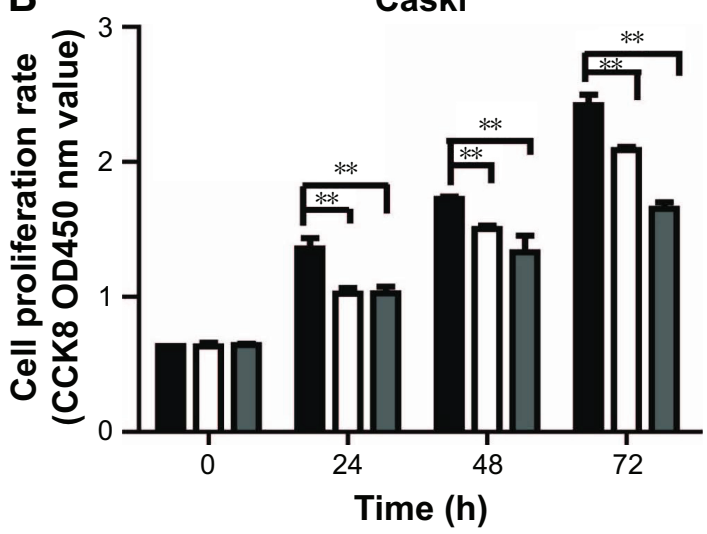

Control

SiRNA-1

siRNA-2

Figure 3 Silencing of matrix metalloproteinase-7 (MMP-7) suppresses cervical cancer cell proliferation in vitro.

Notes: The proliferation of Hela (A) and Caski (B) cells in the control and siRNA-I and siRNA-2 groups was determined by Cell Counting Kit-8 (CCK8) assay at 0, 24, 48, and $72 \mathrm{~h}$. Values are presented as the mean \pm standard error of the mean; $\mathrm{n}=5$. **P $<0.01$. siRNA-I: 5'-ACC CAT TTG ATG GGC CAG GAA-3'; siRNA-2: 5'-TGC AGT GAT GTA TCC AAC CTA-3'. 


\section{A}
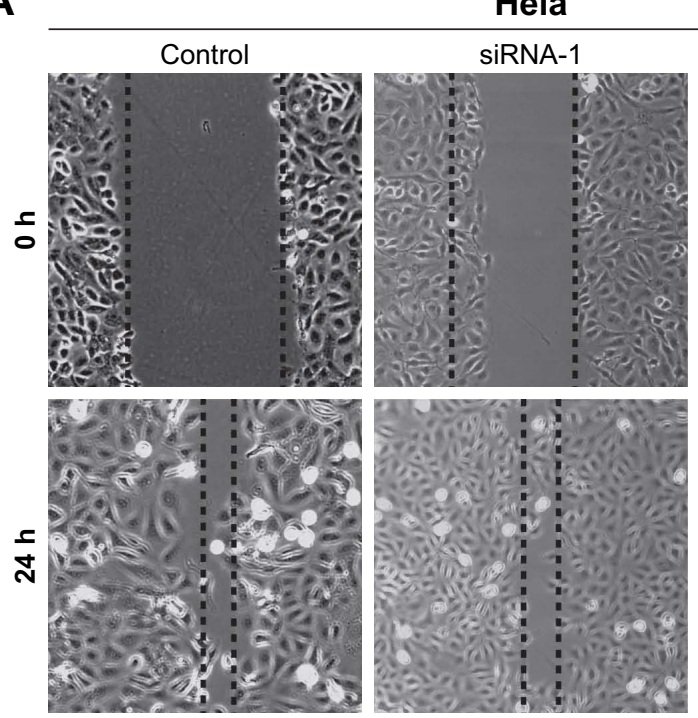

C
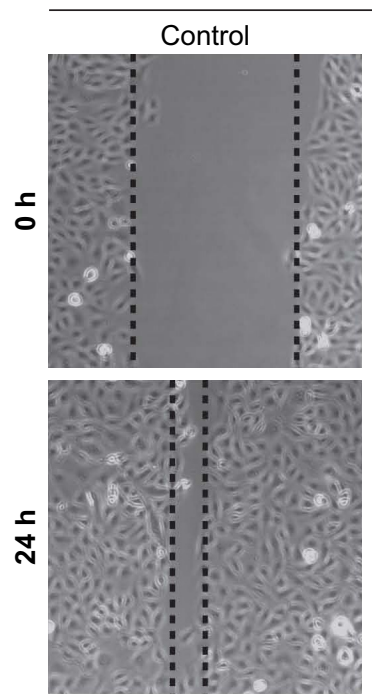

Caski
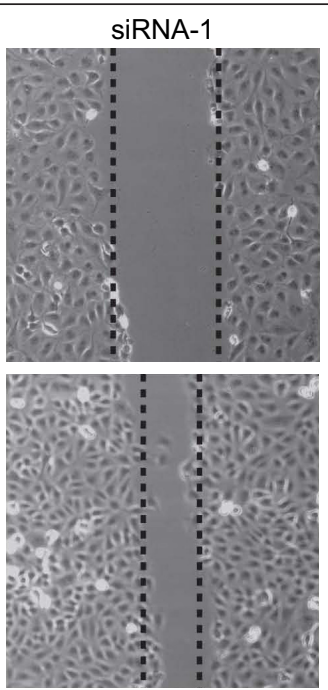
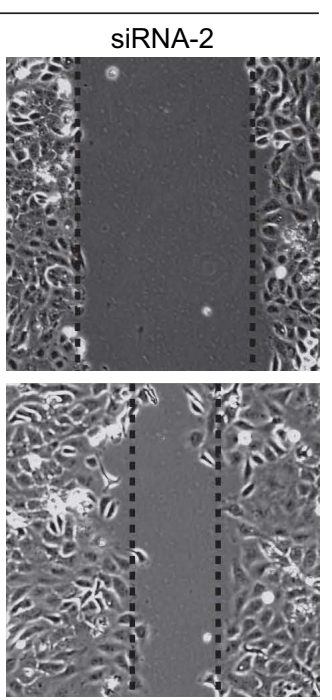

B

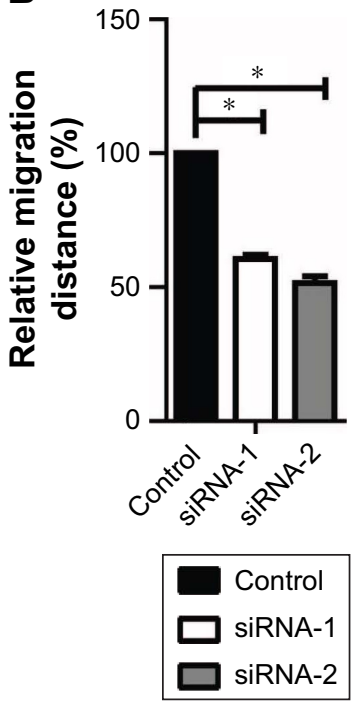

D

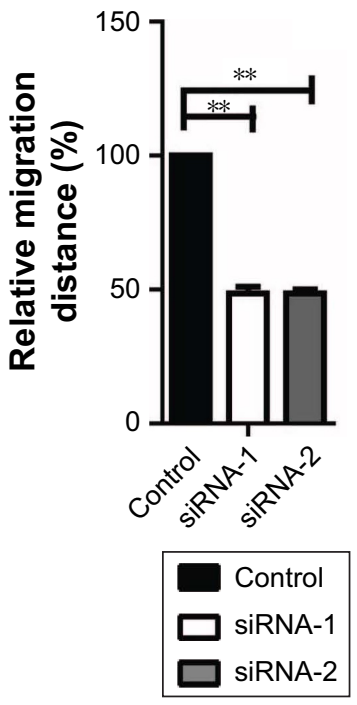

Figure 4 Silencing of matrix metalloproteinase-7 (MMP-7) suppresses cervical cancer cell migration in vitro.

Notes: Representative wound healing images of Hela (A) and Caski (C) cells at 0 and 24 h. The dotted black lines outline the cell boundary. Magnification 200x. Wound healing rates were quantified in both Hela (B) and Caski (D) cells. Data are presented as the mean \pm standard error of the mean; $* P<0.05$; $* * P<0.0$ I. siRNA-I: 5 '-ACC CAT TTG ATG GGC CAG GAA-3'; siRNA-2: 5'-TGC AGT GAT GTA TCC AAC CTA-3'.

between patients with tumor size $\geq 2 \mathrm{~cm}$ and those with tumor size $<2 \mathrm{~cm}(P=0.151$, Figure $7 \mathrm{E})$. There was also no significant difference in MMP-7 levels between patients with vascular invasion compared to patients without vascular invasion $(P=0.936$, Figure $7 \mathrm{~F})$.

\section{MMP-7 mRNA levels are significantly altered by silencing of E6/E7}

Since E6/E7 play a key role in the development of cervical cancer, to further investigate the relationship between E6/E7 and MMP-7, we silenced E6/E7 in Caski and Hela cells and then performed a whole-genome microarray analysis in siRNA-E6/E7 and siRNA-control cells (the details are described in Supplementary materials). The results showed that MMP-7 was significantly downregulated in Caski and Hela siRNA-E6/E7 cells (Figure S2A and B).

\section{Discussion}

Early detection of cervical cancer is crucial for effective treatment and is associated with excellent survival rates. However, the 5-year survival rate for cervical cancer patients with advanced disease is poor ${ }^{29}$ due to cancer invasion and metastasis. ${ }^{30}$ Therefore, the exploration of new diagnostic and prognostic markers for cervical cancer has been a 
A

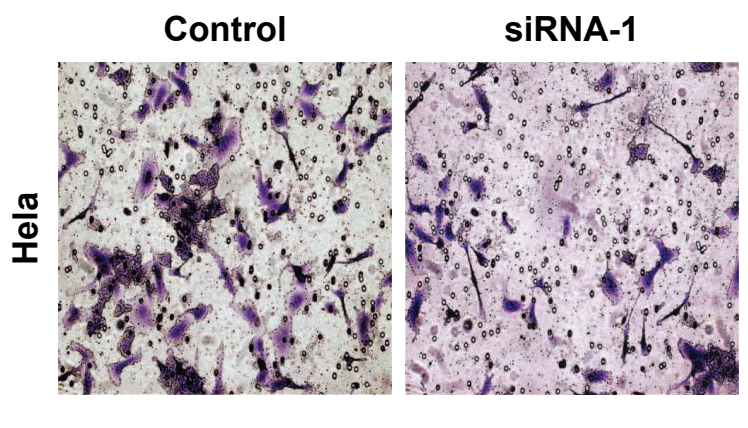

C

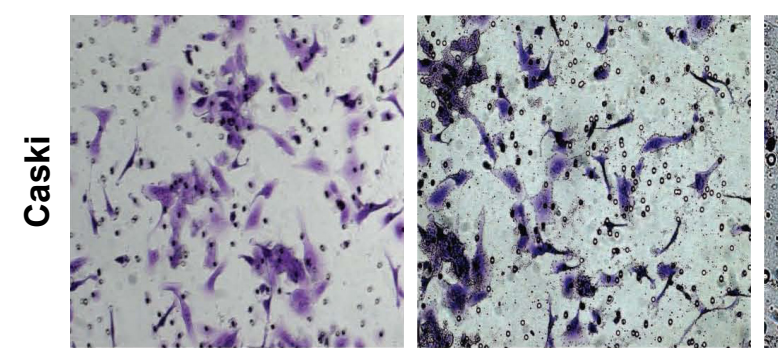

SiRNA-2

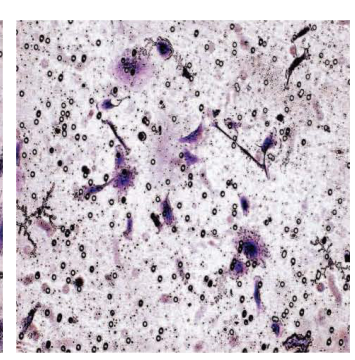

B

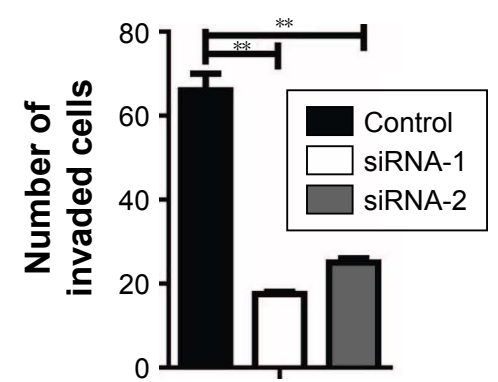

D

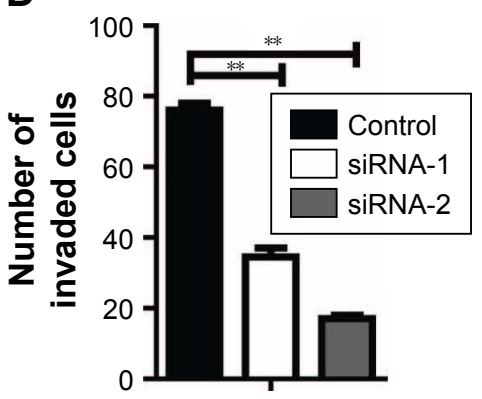

Figure 5 Silencing of matrix metalloproteinase-7 (MMP-7) suppresses cervical cancer cell invasion in vitro.

Notes: (A and C) Representative invasion images from MMP-7-silenced and control cells. Original magnification: 200X. (B and D) Quantification of cells on the lower surface of the membrane was performed with 3 randomly selected fields. Data are presented as the means \pm standard error of the mean; ${ }^{* * P}<0.01$. siRNA-I: 5 '-ACC CAT TTG ATG GGC CAG GAA-3'; siRNA-2: 5'-TGC AGT GAT GTA TCC AAC CTA-3'.

hotspot in the tumor field. In recent years, SCC-Ag has been widely applied to evaluate therapeutic effects and has been identified as a predictive and prognostic factor for cervical carcinoma. ${ }^{31}$ Studies have found that sustained elevation of SCC-Ag reflects persistent disease or recurrence..$^{32}$ However, the clinical value of serum SCC-Ag is still debated. The changes in SCC-Ag levels are not specific to cervical cancer but have also been observed in patients with lung cancer, esophageal SCC, and other benign diseases. ${ }^{33,34}$ Further, the cutoff level for SCC-Ag is still a matter of debate due to the difference in disease stages among patient groups. ${ }^{35}$ Therefore, it appears that SCC-Ag is not an ideal biomarker for predicting outcomes in cervical cancer.

In the past decade, many potential biomarkers have been discovered including circulating proteins, ${ }^{36}$ mutated DNAs, RNAs, ${ }^{37,38}$ and serum proteins. Serum markers are the simplest to measure for routine clinical assessments and epidemiological studies. ${ }^{39}$ Thus, the identification of a novel serum biomarker is an important goal for improving the diagnosis and prognosis of cancer, especially late-stage cervical cancer. ${ }^{40}$ MMPs are circulating proteins that play an important role in cancer as well as in numerous other diseases. It has been reported that the expression of a number of MMPs (including MMP-2 and MMP-9) is highly elevated in invasive cervical carcinomas compared with normal tissues. ${ }^{41,42}$ In some cancer studies, the elevation of MMPs in tumor tissue is thought to contribute to cancer progression through ECM-associated molecules. ${ }^{43,44}$ In the microenvironment, high levels of MMPs are thought to induce EMT. Induction of EMT may then result in the production of more MMPs that can facilitate cancer cell invasion and metastasis.

Studies have found that ECM proteins play an important role in cervical cancer invasion and metastasis. MMP-7 expression is elevated in many human tumors, such as gastric adenocarcinoma, endometrial carcinoma, colorectal cancer, and advanced stage ovarian cancer, and is associated with cancer cell invasion and metastasis. Tanimoto et al suggested that MMP-7 may serve as a therapeutic target for ovarian cancer, ${ }^{23}$ though it remains unclear whether MMP-7 contributes to angiogenesis and tumor progression in HPV-induced cervical cancers.

In the present study, we demonstrated that MMP-7 upregulation correlates with poor prognosis and reduced survival in cervical cancer. In addition, MMP-7 downregulation hampers cell proliferation, migration, and invasion in vitro. Serum MMP-7 concentrations were much higher in cervical cancer patients compared with normal controls. These findings are convincing evidence that MMP-7 plays a 
A

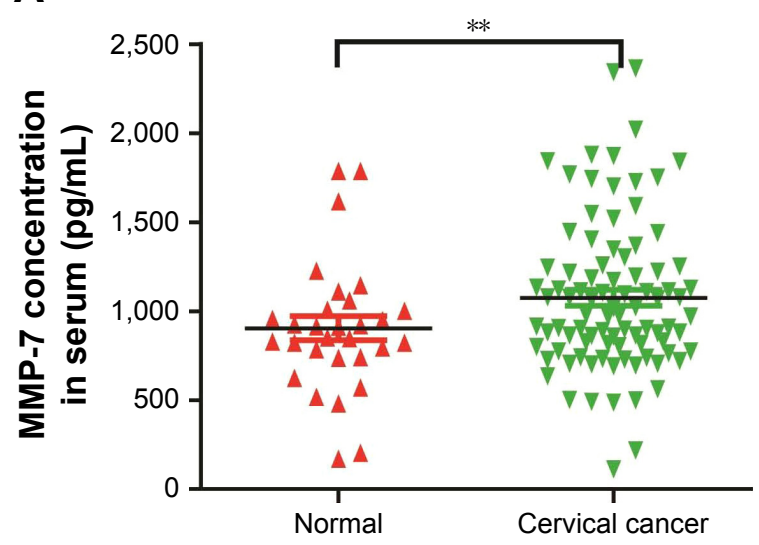

B

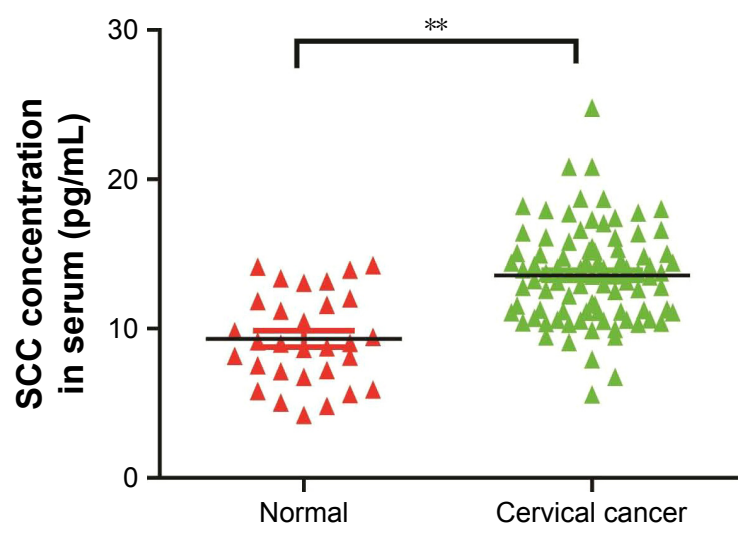

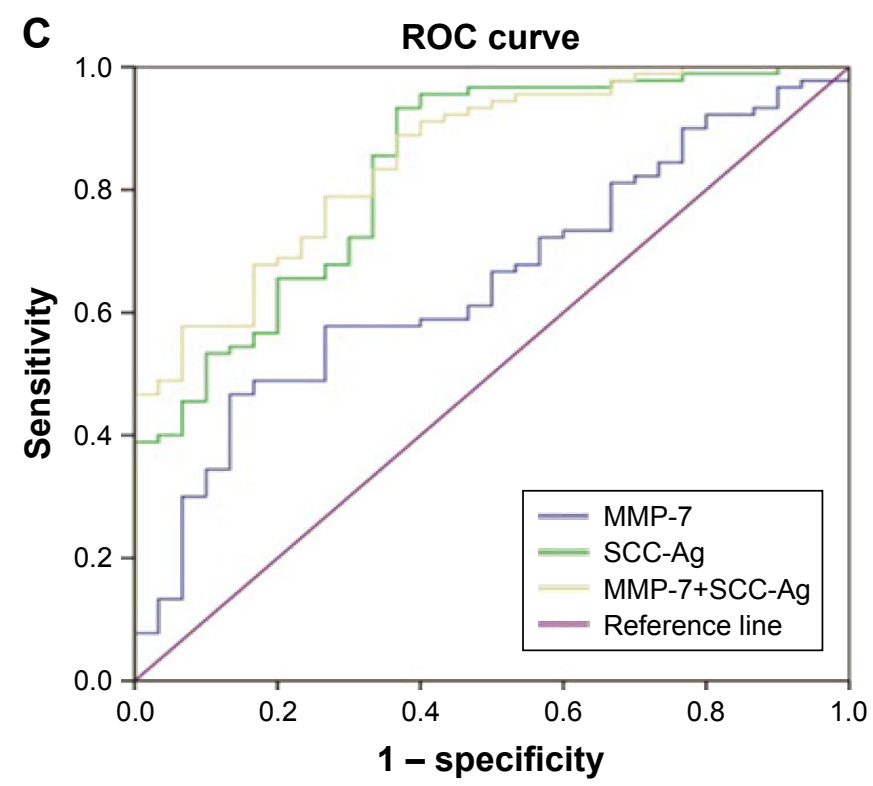

Figure 6 Matrix metalloproteinase-7 (MMP-7) is highly expressed in the serum of cervical cancer patients.

Notes: (A) Comparisons between serum MMP-7 concentrations in healthy people and cervical cancer patients. (B) Comparisons between serum squamous cell carcinoma antigen (SCC-Ag) concentrations in healthy people and cervical cancer patients. (C) Receiver operating characteristic (ROC) curve analysis was performed to predict the clinical value of MMP-7, SCC-Ag, and MMP-7+SCC-Ag levels in cervical cancer prediction. $* * P<0.01$.

significant role in the progression of cervical cancer and has the potential to be a novel biomarker in cervical cancer.

Sheu et al reported that the expression of MMP-2 and MMP-9 was significantly higher in squamous cell carcinoma and that the expression of these 2 MMPs was associated with clinical stage, nodal metastasis, and recurrence. Meanwhile, the expression of MMP-7 was much lower. ${ }^{41}$ However, in our study, we found that MMP-7 mRNA and protein expression levels were significantly higher in cervical cancer samples than in normal cervical tissues and serum. This is possibly due to differences in clinical sample characteristics such as patient location, age, race, and detection methods. In the future, we will collect more clinical tissues and serum to verify our results.

Table 2 Sensitivity and specificity of MMP-7, SCC-Ag, and MMP-7 combined with SCC-Ag in the detection of cervical cancer

\begin{tabular}{|c|c|c|c|c|}
\hline Group & AUC (95\% Cl) & Sensitivity & Specificity & $\begin{array}{l}\text { Youden's } \\
\text { index }\end{array}$ \\
\hline MMP-7 & $0.650 \pm 0.054(0.544-0.756)$ & $46.7 \%$ & $86.7 \%$ & 0.334 \\
\hline SCC-Ag & $0.769 \pm 0.053(0.665-0.873)$ & $94.4 \%$ & $66.7 \%$ & 0.611 \\
\hline MMP-7+SCC-Ag & $0.806 \pm 0.047(0.713-0.899)$ & $84.4 \%$ & $73.3 \%$ & 0.578 \\
\hline
\end{tabular}

Abbreviations: AUC, area under receiver operating characteristic curve; MMP-7, matrix metalloproteinase-7; SCC-Ag, squamous cell carcinoma antigen. 
A

Lymph metastasis

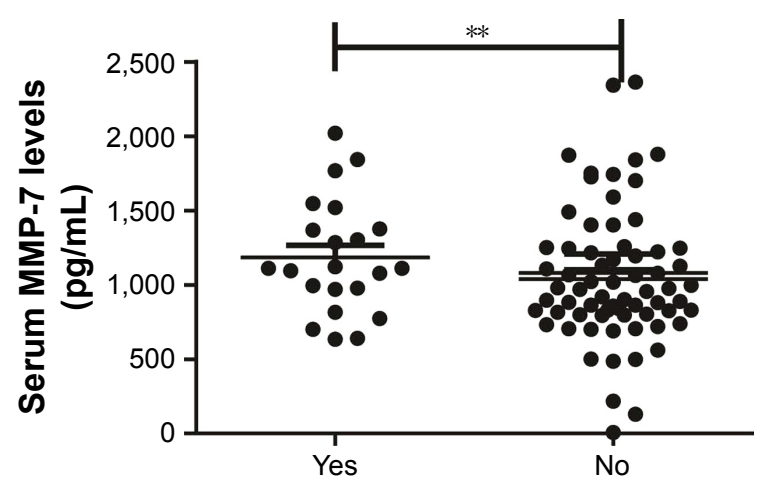

C

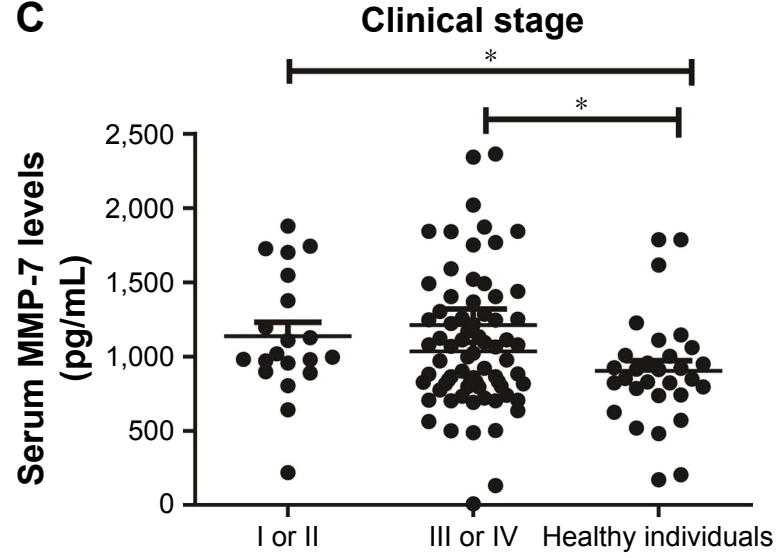

B

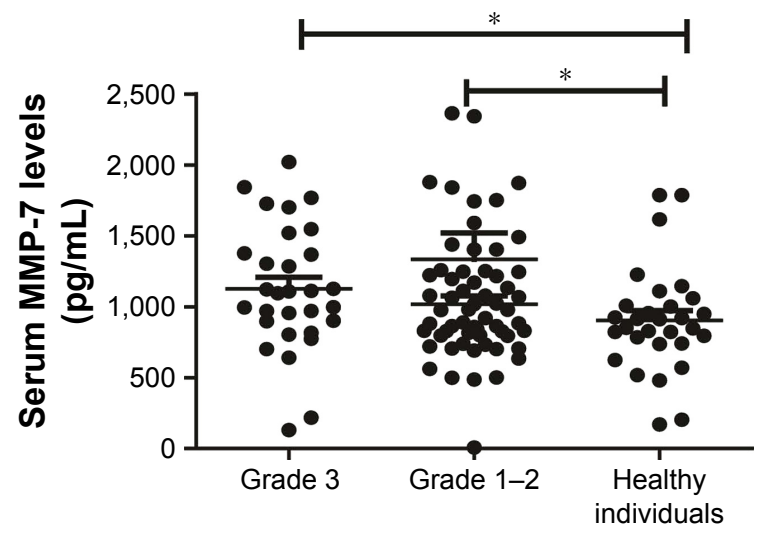

D Depth of invasion

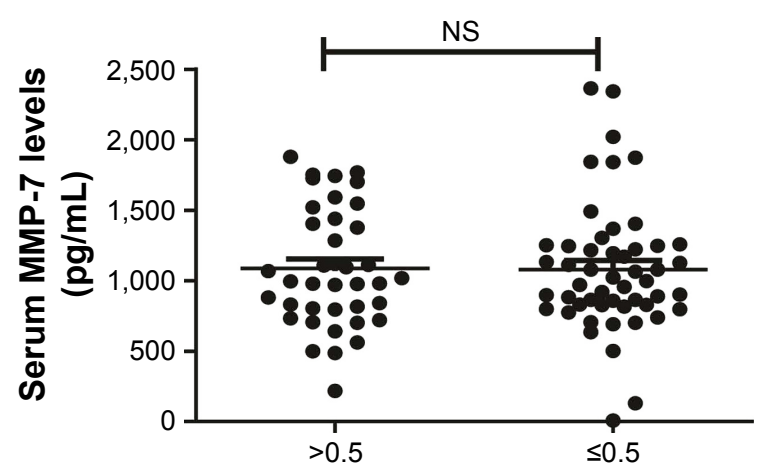

E

Tumor size

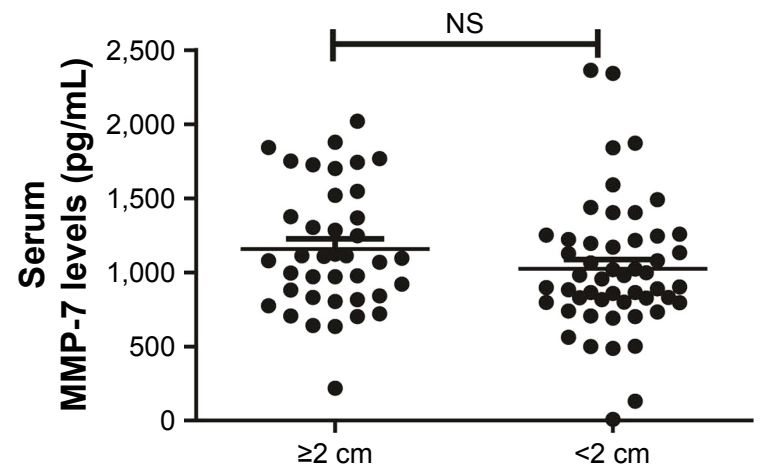

$\mathbf{F}$

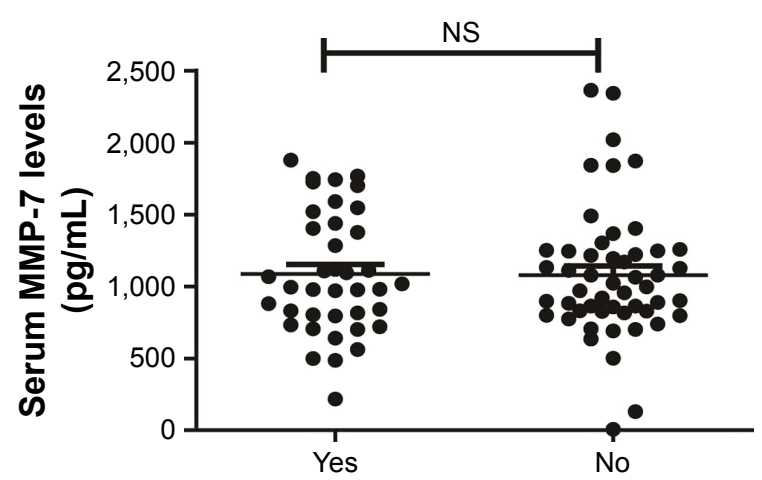

Figure 7 Analysis of correlation between matrix metalloproteinase-7 (MMP-7) expression and clinical data.

Notes: (A) Serum MMP-7 levels in patients with lymph metastasis compared to those without lymph metastasis. (B) Serum MMP-7 levels in patients with pathology grade 3 , or grades I or 2 compared with healthy individuals. (C) Serum MMP-7 levels in patients with clinical stage I or II, or III or IV, compared with healthy individuals. (D) Serum MMP-7 levels in patients with tumor invasion depth $>0.5$ compared to patients with tumor invasion depth $\leq 0.5$. (E) Serum MMP-7 levels in patients with tumors $\geq 2$ cm compared to those with tumors $<2 \mathrm{~cm}$. (F) Serum MMP-7 levels in patients with vascular invasion compared to those without vascular invasion. Data are presented as the mean \pm standard error of the mean; $* P<0.05 ; * * P<0.01$.

Abbreviation: NC, no sense.

Previous studies have reported that MMP-7 is well correlated with tumor malignancy and metastasis, especially with colon cancer liver metastasis. ${ }^{45,46}$ Tanimoto et al reported that MMP-7 may serve as a useful marker for detection and as a therapeutic target for ovarian cancer. ${ }^{23}$ This is consistent with our study, as we also found that silencing of MMP-7 suppressed cell proliferation, migration, and invasion in vitro and that serum MMP-7 concentrations were much higher in cervical cancer patients compared with normal controls. Additionally, higher levels of MMP-7 were associated with advanced tumor stage, lymph metastasis, and pathology grade. Patients with high tumor stage or lymph metastasis 
were thought to have a poor prognosis and were more susceptible to metastasis, recurrence, and death. Therefore, determining the expression of MMP-7 in cervical tissues via biopsy and examining serum levels of MMP-7 in cervical cancer patients can provide significant guidance for deciding on a preferred treatment modality for patients with cervical cancer.

Currently, persistent HPV infection is recognized as the main cause of cervical cancer. HPV16 and HPV18 are the most carcinogenic HPVs. To date, the mechanism by which MMPs promote cancer cell invasion and migration is unclear. Some studies have reported that MMPs (including MMP-2 and MT1-MMP) are upregulated by HPV16 oncoproteins in cervical cancer to promote cancer cell invasiveness. Other studies have shown that MMPs can induce EMT, subsequently leading to the production of more MMPs that can facilitate cancer cell invasion and metastasis. During our in vitro experiments, we did not see differences in cell shape between siRNA-MMP-7 cells and control cells. This is possibly because MMP-7 promotes cervical cancer cell invasion by mechanisms other than EMT. To further explore the relationship between MMP-7 and HPV oncoproteins, we knocked down HPV16 and HPV18 E6/E7 by transfecting HPV16-positive Caski cells and HPV18-positive Hela cells with siRNA-E6/E7. We then performed a whole-genome microarray analysis in siRNA-HPV16/18 E6/E7 and siRNAcontrol Caski and Hela cells. The results showed that MMP-7 was significantly downregulated in siRNA-E6/E7-treated cells (Figure S2A and B). It is well known that the HPV oncoproteins E6 and E7 target the tumor suppressors P53 and retinoblastoma protein. These data suggest that MMP-7 is involved in cell proliferation, migration, and invasion, which may depend on upregulation by HPV16/18 oncoproteins. We will further study the mechanism by which HPV16/18 regulates MMP-7 to promote cervical cancer invasiveness.

The limited healthy serum control sample size of our study may result in conclusion biases. In the future, we need a larger sample size to further verify the value of MMP-7 in cervical cancer.

\section{Conclusion}

Our study confirmed the aberrant expression and clinical significance of MMP-7 in cervical cancer. Moreover, we found that MMP-7 knockdown suppressed cervical cancer cell proliferation, invasion, and migration. MMP-7 may represent a novel indicator for identifying high-risk patients and could potentially serve as a clinically relevant biomarker for predicting cervical cancer patient outcomes.

\section{Acknowledgments}

This work was supported by the Medical and Health Plan of Zhejiang (grant number 2015KYA198) and the Ningbo Natural Science Foundation (grant numbers 2015A610228, 2016A610160, and 2016A610162). We would like to thank the Central Laboratory of Ningbo First Hospital. We also thank American Journal Experts for English language editing.

\section{Disclosure}

The authors report no conflicts of interest in this work.

\section{References}

1. Yuan H, Krawczyk E, Blancato J, et al. HPV positive neuroendocrine cervical cancer cells are dependent on Myc but not E6/E7 viral oncogenes. Sci Rep. 2017;7:45617.

2. Chen W, Zheng R, Baade PD, et al. Cancer statistics in China, 2015. CA Cancer J Clin. 2016;66(2):115-132.

3. Kitchener HC, Castle PE, Cox JT. Chapter 7: achievements and limitations of cervical cytology screening. Vaccine. 2006;24 Suppl 3 : S3/63-70.

4. Song N, Sung H, Choi JY, et al. Preoperative serum levels of matrix metalloproteinase-2 (MMP-2) and survival of breast cancer among Korean women. Cancer Epidemiol Biomarkers Prev. 2012;21(8): 1371-1380.

5. Gadducci A, Tana R, Cosio S, Genazzani AR. The serum assay of tumour markers in the prognostic evaluation, treatment monitoring and follow-up of patients with cervical cancer: a review of the literature. Crit Rev Oncol Hematol. 2008;66(1):10-20.

6. Oh J, Lee HJ, Lee TS, Kim JH, Koh SB, Choi YS. Clinical value of routine serum squamous cell carcinoma antigen in follow-up of patients with locally advanced cervical cancer treated with radiation or chemoradiation. Obstet Gynecol Sci. 2016;59(4):269-278.

7. Bae SN, Namkoong SE, Jung JK, et al. Prognostic significance of pretreatment squamous cell carcinoma antigen and carcinoembryonic antigen in squamous cell carcinoma of the uterine cervix. Gynecol Oncol. 1997;64(3):418-424.

8. Gaarenstroom KN, Kenter GG, Bonfrer JM, et al. Can initial serum cyfra 21-1, SCC antigen, and TPA levels in squamous cell cervical cancer predict lymph node metastases or prognosis? Gynecol Oncol. 2000; 77(1):164-170.

9. Yuan CC, Wang PH, Ng HT, Tsai LC, Juang CM, Chiu LM. Both TPA and SCC-Ag levels are prognostic even in high-risk stage Ib-IIa cervical carcinoma as determined by a stratification analysis. Eur J Gynaecol Oncol. 2002;23(1):17-20.

10. Reesink-Peters N, van der Velden J, Ten Hoor KA, et al. Preoperative serum squamous cell carcinoma antigen levels in clinical decision making for patients with early-stage cervical cancer. J Clin Oncol. 2005;23(7):1455-1462.

11. Zhang G, Miyake M, Lawton A, Goodison S, Rosser CJ. Matrix metalloproteinase-10 promotes tumor progression through regulation of angiogenic and apoptotic pathways in cervical tumors. BMC Cancer. 2014;14:310.

12. McGuire JK, Li Q, Parks WC. Matrilysin (matrix metalloproteinase-7) mediates E-cadherin ectodomain shedding in injured lung epithelium. Am J Pathol. 2003;162(6):1831-1843

13. Tan RJ, Liu Y. Matrix metalloproteinases in kidney homeostasis and diseases. Am J Physiol Renal Physiol. 2012;302(11):F1351-F1361.

14. Mitsiades N, Yu WH, Poulaki V, Tsokos M, Stamenkovic I. Matrix metalloproteinase-7-mediated cleavage of Fas ligand protects tumor cells from chemotherapeutic drug cytotoxicity. Cancer Res. 2001;61(2): 577-581. 
15. Zhou D, Tian Y, Sun L, et al. Matrix metalloproteinase-7 is a urinary biomarker and pathogenic mediator of kidney fibrosis. $J$ Am Soc Nephrol. 2017;28(2):598-611.

16. Rosas IO, Richards TJ, Konishi K, et al. MMP1 and MMP7 as potential peripheral blood biomarkers in idiopathic pulmonary fibrosis. PLoS Med. 2008;5(4):e93.

17. Hojilla CV, Mohammed FF, Khokha R. Matrix metalloproteinases and their tissue inhibitors direct cell fate during cancer development. $\mathrm{Br} J$ Cancer. 2003;89(10):1817-1821.

18. Kaewprag J, Umnajvijit W, Ngamkham J, Ponglikitmongkol M. HPV16 oncoproteins promote cervical cancer invasiveness by upregulating specific matrix metalloproteinases. PLoS One. 2013;8(8):e71611.

19. Wilson CL, Matrisian LM. Matrilysin: an epithelial matrix metalloproteinase with potentially novel functions. Int J Biochem Cell Biol. 1996;28(2):123-136.

20. Ii M, Yamamoto H, Adachi Y, Maruyama Y, Shinomura Y. Role of matrix metalloproteinase-7 (matrilysin) in human cancer invasion, apoptosis, growth, and angiogenesis. Exp Biol Med (Maywood). 2006; 231(1):20-27.

21. Hadler-Olsen E, Winberg JO, Uhlin-Hansen L. Matrix metalloproteinases in cancer: their value as diagnostic and prognostic markers and therapeutic targets. Tumour Biol. 2013;34(4):2041-2051.

22. Yin JG, Liu XY, Wang B, et al. Gene expression profiling analysis of ovarian cancer. Oncol Lett. 2016;12(1):405-412.

23. Tanimoto H, Underwood LJ, Shigemasa K, et al. The matrix metalloprotease pump-1 (MMP-7, Matrilysin): a candidate marker/target for ovarian cancer detection and treatment. Tumour Biol. 1999;20(2):88-98.

24. Hu X, Li D, Zhang W, Zhou J, Tang B, Li L. Matrix metalloproteinase-9 expression correlates with prognosis and involved in ovarian cancer cell invasion. Arch Gynecol Obstet. 2012;286(6):1537-1543.

25. Dong Z, Xu X, Du L, et al. Leptin-mediated regulation of MT1-MMP localization is KIF1B dependent and enhances gastric cancer cell invasion. Carcinogenesis. 2013;34(5):974-983.

26. Mori M, Barnard GF, Mimori K, Ueo H, Akiyoshi T, Sugimachi K. Overexpression of matrix metalloproteinase-7 mRNA in human colon carcinomas. Cancer. 1995;75(6 Suppl):1516-1519.

27. Rhodes DR, Yu J, Shanker K, et al. ONCOMINE: a cancer microarray database and integrated data-mining platform. Neoplasia. 2004; 6(1):1-6.

28. Zhang Z, Chometon G, Wen T, et al. Migration of epithelial cells on laminins: RhoA antagonizes directionally persistent migration. Eur $J$ Cell Biol. 2011;90(1):1-12.

29. Denny L. Cervical cancer: prevention and treatment. Discov Med. 2012;14(75):125-131.

30. Chidyaonga-Maseko F, Chirwa ML, Muula AS. Underutilization of cervical cancer prevention services in low and middle income countries: a review of contributing factors. Pan Afr Med J. 2015;21:231.

31. Wang Y, Cui T, Du L, et al. The correlation between the serum squamous carcinoma antigen and the prognosis of recurrent cervical squamous carcinoma. J Clin Lab Anal. 2017;31(1):e22020.
32. Ouyang F, Liu J, Xia M, et al. GINS2 is a novel prognostic biomarker and promotes tumor progression in early-stage cervical cancer. Oncol Rep. 2017;37(5):2652-2662.

33. Li J, Chen P, Mao CM, Tang XP, Zhu LR. Evaluation of diagnostic value of four tumor markers in bronchoalveolar lavage fluid of peripheral lung cancer. Asia Pac J Clin Oncol. 2014;10(2):141-148.

34. Cao X, Zhang L, Feng GR, et al. Preoperative Cyfra21-1 and SCC-Ag serum titers predict survival in patients with stage II esophageal squamous cell carcinoma. J Transl Med. 2012;10:197.

35. Molina R, Filella X, Augé JM, et al. CYFRA 21.1 in patients with cervical cancer: comparison with SCC and CEA. Anticancer Res. 2005; 25(3A):1765-1771.

36. Skerenova M, Mikulova V, Capoun O, Zima T, Tesarova P. Circulating tumor cells and serum levels of MMP-2, MMP-9 and VEGF as markers of the metastatic process in patients with high risk of metastatic progression. Biomed Pap Med Fac Univ Palacky Olomouc Czech Repub. 2017;161(3):272-280.

37. Tsai HC, Baylin SB. Cancer epigenetics: linking basic biology to clinical medicine. Cell Res. 2011;21(3):502-517.

38. Hundt S, Haug U, Brenner H. Blood markers for early detection of colorectal cancer: a systematic review. Cancer Epidemiol Biomarkers Prev. 2007;16(10):1935-1953.

39. Malaguarnera G, Giordano M, Paladina I, Berretta M, Cappellani A, Malaguarnera M. Serum markers of hepatocellular carcinoma. Dig Dis Sci. 2010;55(10):2744-2755.

40. Wagner PD, Verma M, Srivastava S. Challenges for biomarkers in cancer detection. Ann N Y Acad Sci. 2004;1022:9-16.

41. Sheu BC, Lien HC, Ho HN, et al. Increased expression and activation of gelatinolytic matrix metalloproteinases is associated with the progression and recurrence of human cervical cancer. Cancer Res. 2003; 63(19):6537-6542.

42. Vazquez-Ortiz G, Pina-Sanchez P, Vazquez K, et al. Overexpression of cathepsin F, matrix metalloproteinases 11 and 12 in cervical cancer. BMC Cancer. 2005;5:68.

43. Lohi J, Lehti K, Valtanen H, Parks WC, Keski-Oja J. Structural analysis and promoter characterization of the human membrane-type matrix metalloproteinase-1 (MT1-MMP) gene. Gene. 2000;242(1-2):75-86.

44. Qin L, Liao L, Redmond A, et al. The AIB1 oncogene promotes breast cancer metastasis by activation of PEA3-mediated matrix metalloproteinase 2 (MMP2) and MMP9 expression. Mol Cell Biol. 2008;28(19):5937-5950.

45. Adachi Y, Yamamoto H, Itoh F, Hinoda Y, Okada Y, Imai K. Contribution of matrilysin (MMP-7) to the metastatic pathway of human colorectal cancers. Gut. 1999;45(2):252-258.

46. Ishikawa T, Ichikawa Y, Mitsuhashi M, et al. Matrilysin is associated with progression of colorectal tumor. Cancer Lett. 1996;107(1):5-10. 


\section{Supplementary materials}

Whole-genome microarray construction and transcriptional profiling microarray

A whole-genome microarray of silencing E6/E7-group and control group in Caski cells was performed at Shanghai BoHao Biotechnology Co. Ltd (Shanghai, China) according to manufacturer's protocol. In brief, Cy3-labeled cRNA from 2 biological replicates was hybridized by using Gene Expression Hybridization Kit. After 20 hours, slides were washed in staining dishes with Gene Expression Wash Buffer Kit. The chip contains 42,494 probes, including $5 \times 301$ repeat probes and 2,118 internal control probes. The reference database for probe design is UCSC hg18 (Build NCBI 36, March 2006). The spacing of the probe is $43 \mathrm{~KB}$. A transcriptional profiling microarray of silencing E6/E7 group and control group in Caski cell lines was done according to the manufacturer's protocol. In brief, labeled cRNA was hybridized to Illumina Genome-Wide Expression BeadChips representing 43,000 human transcripts, at $58^{\circ} \mathrm{C}$ overnight. The array was washed and blocked, and hybridized beads were stained with Streptavidin Cy3 (Sigma, St Louis, MO, USA). The chips were scanned using Agilent Microarray Scanner.

Table SI Sequences of the primers used for the analysis of mRNA gene expression

\begin{tabular}{lll}
\hline Gene & Forward primer & Reverse primer \\
\hline GAPDH & 5'AGGTCGGTGTGAACGGATTTG-3' $^{\prime}$ 'AG'-TGTAGACCATGTAGTTGAGGTCA-3' \\
MMP-7 & 5'-GTCTCTGGACGGCAGCTATG-3' $^{\prime}$ & 5'-GATAGTCCTGAGCCTGTTCCC-3' $^{\prime}$ \\
\hline
\end{tabular}

Abbreviation: MMP-7, matrix metalloproteinase-7.

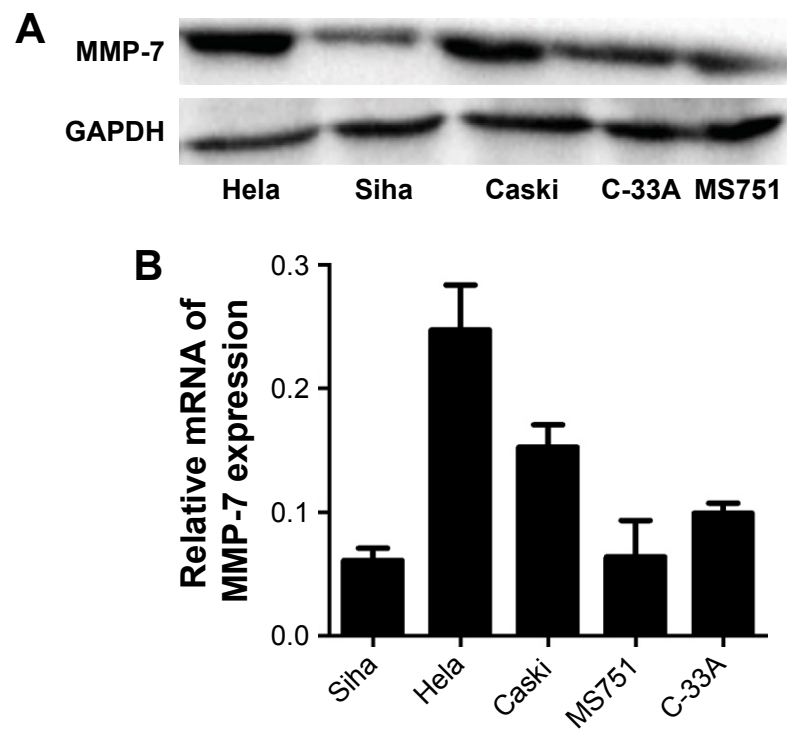

Figure SI The expression (B) of matrix metalloproteinase-7 (MMP-7) in cell lysates from Hela, Siha, Caski, C-33A, and MS75I cells was detected by Western blot analysis (A) and real-time polymerase chain reaction. 
A

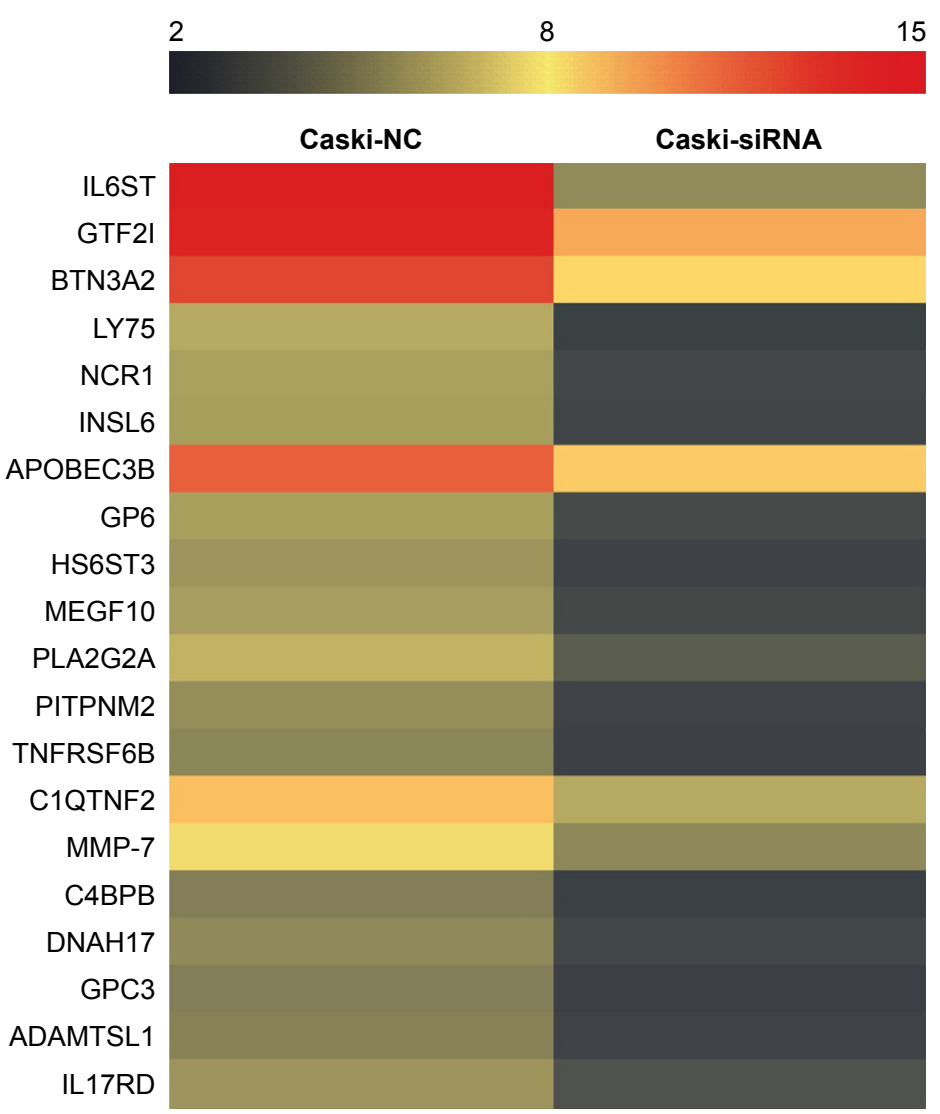

B 2

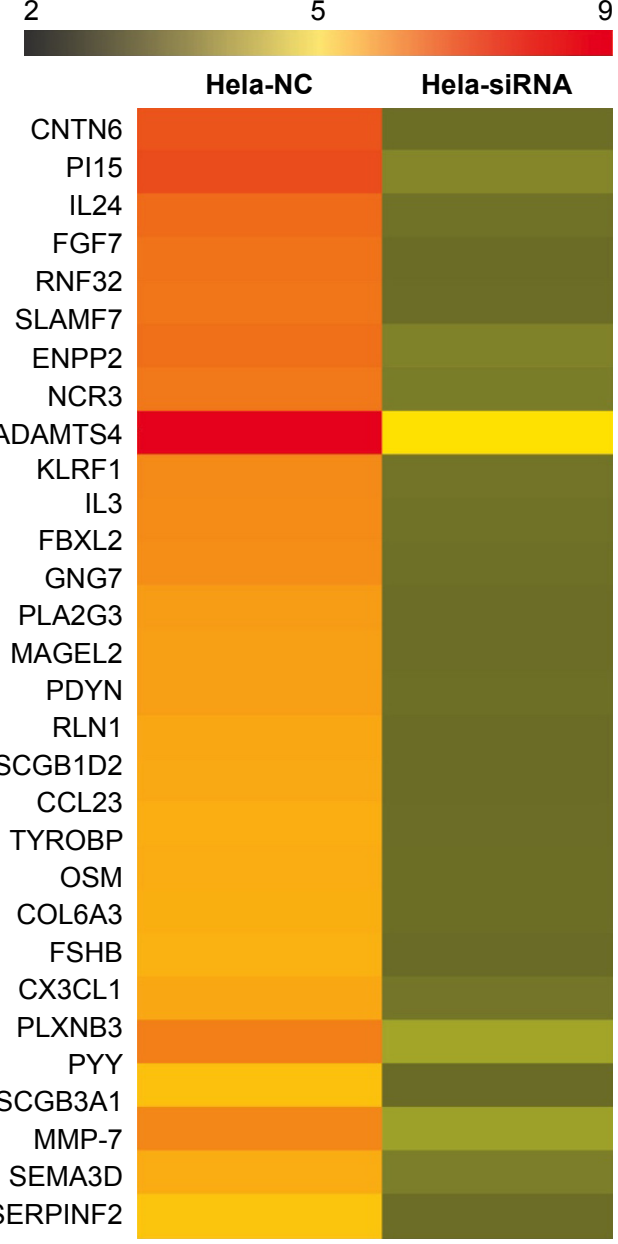

Figure S2 Extracellular matrix expression profile is altered by silencing of human papillomavirus (HPV) I6/I8-E6/E7 in Caski and Hela cells.

Notes: (A) In total, 20 genes that encode extracellular secreted proteins were significantly downregulated in Caski cells with silencing of E6/E7, as compared with control cells (fold change $>3$ and $P<0.05$ ). (B) Thirty genes that encode extracellular secreted proteins were significantly downregulated in Hela cells with silencing of E6/E7, as compared with control cells (fold change $>3$ and $P<0.05$ ).

Abbreviation: NC, normal control.

OncoTargets and Therapy

\section{Publish your work in this journal}

OncoTargets and Therapy is an international, peer-reviewed, open access journal focusing on the pathological basis of all cancers, potential targets for therapy and treatment protocols employed to improve the management of cancer patients. The journal also focuses on the impact of management programs and new therapeutic agents and protocols on

\section{Dovepress}

patient perspectives such as quality of life, adherence and satisfaction. The manuscript management system is completely online and includes a very quick and fair peer-review system, which is all easy to use. Visit http://www.dovepress.com/testimonials.php to read real quotes from published authors. 